\title{
Pattern of rheumatic heart disease in patients admitted at tertiary care centre of Nepal
}

\author{
Prabha Chapagain Koirala ${ }^{1}$, Ram Kishor. Sah ${ }^{1}$, Deewaker Sharma ${ }^{2}$
}

${ }^{1}$ Department of Cardiology, National Academy of Medical Sciences, Kathmandu.

${ }^{2}$ Department of Cardiology, Shahid Gangalal National Heart Centre, Kathmandu.

Corresponding Author: Prabha Chapagain

National Academy of Medical Sciences, Shahid Gangalal National Heart Centre, Kathmandu

Email: drprabhakoirala@yahoo.com

\begin{abstract}
Background and Aims: As in other developing countries, Rheumatic Heart Disease (RHD) remains a major public health problem in Nepal. The most commonly affected people are children and adults in their productive years of age. The major contributing factors for high prevalence of Rheumatic Heart Disease in developing countries are poverty, illiteracy and limited access to healthcare services. The study was done to assess the basic pattern of Rheumatic Heart Disease among patients admitted at tertiary care center of Nepal: Shahid Gangalal National Heart Center.

Methods: It is a cross sectional prospective study done among the patients admitted in Shahid Gangalal National Heart Center, Kathmandu.

Results: RHD was more common among patients of age group 10-40 years, the most common age being 31-40 years (28.5\%), with the male female ratio 1:1.6. Majority of the admitted patients had come from Central Development Region, and least number of patients had come from Far Western Region. About $46.5 \%$ of patients were illiterate and majority of patients were without any income source. Mitral valve was the most commonly affected valve (98.2\%) and mitral regurgitation was the most common valvular lesion.

Conclusion: RHD mainly affects children and young people of low socioeconomic group. In our study, mitral valve was the most commonly affected valve and mitral regurgitation was the most common valvular lesion. Mitral Stenosis was statistically significant in female patients while aortic regurgitation as well as aortic stenosis were significant in male patients.
\end{abstract}

Key words: Aortic Regurgitation, Mitral Regurgitation, Mitral Stenosis, Rheumatic Heart Disease.

DOI: http://dx.doi.org/10.3126/njh.v15i1.19713

\section{Introduction}

Rheumatic fever complicated by rheumatic heart disease (RHD) remains a major contributor to morbidity and premature death among the socioeconomically underprivileged working age population of developing countries. ${ }^{1}$ RHD ranks among the important non-communicable diseases and is a substantial health care challenge in less privileged regions of the world. It was estimated that worldwide 15.6 million people have rheumatic heart disease and that there are 470,000 new cases of rheumatic fever and 233,000 deaths attributable to rheumatic fever or rheumatic heart disease each year. ${ }^{2}$ The worst affected areas are Sub-Saharan Africa, South-Central Asia, the Pacific and indigenous populations of Australia and New Zealand. Up to 1 percent of all school children in Africa, Asia, the Eastern Mediterranean Region, and Latin America show signs of disease. ${ }^{3}$ The mortality rate per 100000 population varied from 1.8 in the WHO Region of the Americas to 7.6 in WHO South-East Asia Region. Prevalence rates of RHD from screening studies in Southeast Asian countries range from 0.7 to 22 per 1000 children using traditional cardiac auscultation and from 20 to 51 per 1000 children using echocardiography. ${ }^{5-8}$ As in other developing countries RHD remains a major public health problem in Nepal.

This study assesses some basic pattern of RHD such as distribution by age, sex, ethnicity, prevalence of RHD according to geographical region, most common type of valvular lesion and, commonly affected valve which will help the concerned people to initiate and implement appropriate programmes to reduce the burden of RHD in Nepal

\section{Methods}

It is a single center prospective, cross sectional study done at Shahid Gangalal National Heart Center (SGNHC), Kathmandu from September 2016 to February 2017. The study protocol was approved by the Ethical Committee of NAMS, Bir Hospital. Informed consent was taken either from the patient or from their guardian. Altogether 256 diagnosed cases of RHD admitted in SGNHC during study period were enrolled in the study. 
Inclusion Criteria:

- Patients admitted in SGNHC and diagnosed with RHD

- Patients of all age groups.

- History, clinical examination and ECHO criteria were used for diagnosis of RHD

\section{Exclusion Criteria}

- Patient with valvular heart disease of non- rheumatic origin, diagnosed with history, clinical examination and ECHO findings

- Patient with congenital heart disease.

Patients who were admitted and diagnosed as a case of RHD in SGNHC were taken as a case of RHD and included in the study. Questions about demographic features like age, sex, address, occupation, literacy level, ethnicity, history of disease were asked and clinical examination was done by the principle investigator. Echocardiographic findings of affected valves (mitral and aortic), types of lesion, (regurgitation and stenosis) were collected by the principle investigator. Echocardiography was done in all patients by the cardiologist of SGNHC. Diagnosis of RHD was made with history, clinical examination and according to World Heart Federation criteria for echocardiographic diagnosis of RHD'. The ECHO machine used were Philips X Matrix and Philips Epi Q7c.

\section{Statistical Analysis}

The Statistical Analysis was done using the SPSS Version 23 Software (SPSS Inc., Chicago). Descriptive statistics was used to describe and summarized the data. Categorical variables were presented as percentages and frequency p-value $<0.05$ was considered as statistically significant. For the calculation of $\mathrm{p}$-value Pierson $\mathrm{x}^{2}$ test or likelihood ratio was used."

\section{Results}

Altogether 256 patients were included in the study. Their age ranged from 6 years to 75 years with the mean age $32.8 \pm 14.1$ years. $157(61 \%)$ patients were female and 99 (39\%) were male. The male to female ratio was 1:1.6.

\section{Age distribution}

Most commonly affected age group was 31-40 (28.5\%) years followed by $21-30(21.5 \%), 11-20(20.7 \%)$ and $41-$ $50(14.8 \%)$ years.

Figure: 1.

\section{AGE DISTRIBUTION OF STUDY POPULATION}

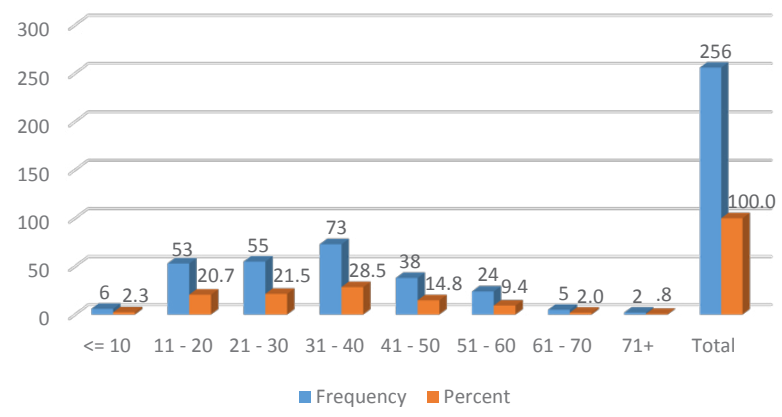

\section{Geographical Distribution:}

Region: Among the admitted patients, majority of the patients had come from Central Development Region 33.2\% followed by Western Development Region 25.0\%, Eastern
Development Region 21.1.\%, Mid-Western Development Region $16.4 \%$ and least number of patients had come from Far Western Region 4.3\%.

Figure: 2 .

\section{DISTRIBUTION OF THE PATIENTS ACCORDING TO} REGION

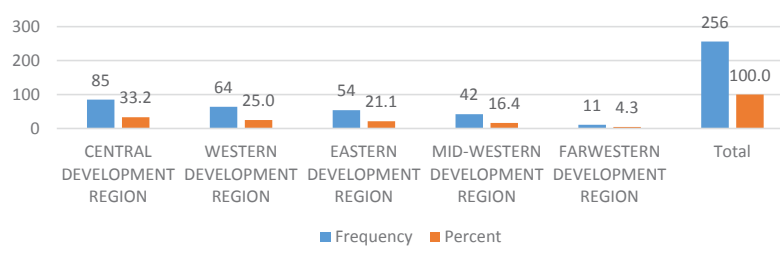

Majority of patients were from Bagmati (17.6\%), Lumbini (12.1\%), Gandaki (9.8\%), Janakpur (9.8\%), Rapti (9.0\%) and Sagarmatha $(9.4 \%)$. Least number of patients were from Karnali (1.2\%), Seti (2.3\%) and Mahakali (2.0\%)

Figure: 3.

\section{DISTRIBUTION OF PATIENTS ACCORDING TO ZONE}

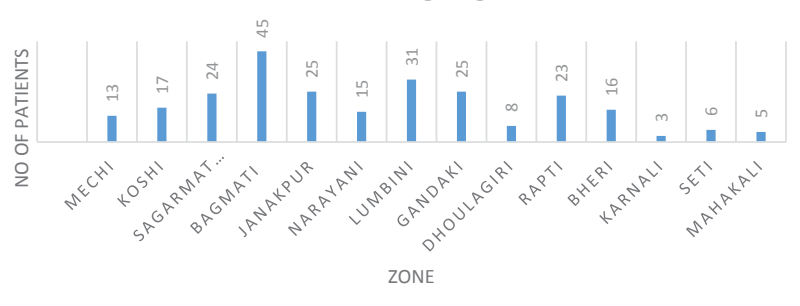

\section{Occupation of the Patients}

$50 \%$ of patients were home maker, $20 \%$ were student, $3.9 \%$ were daily wage workers and $15.2 \%$ were farmers all with no income source while $2.3 \%$ were migrant workers. Only $5.5 \%$ were doing some income generating work like shop keeping, tailoring, beauty-parlor, driving etc. and 1.6\% were teachers with regular income source.

\section{Figure: 4.}

\section{OCCUPATION OF STUDY POPULATION}

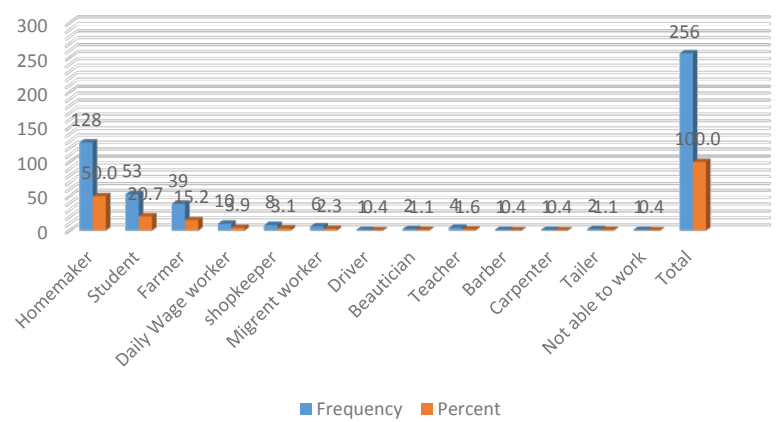

\section{Literacy}

The literacy rate was also very low among the study group. $46.5 \%$ patients were illiterate who did not know how to read and write, $22.3 \%$, had primary level education (1 to 5 class), $9 \%$ had lower secondary level education (6 to 8 class), $15.6 \%$ patients had secondary to SLC level education $(9,10$ and SLC passed), 3.9\% patients had higher secondary level education (11 and 12 class), while $2 \%$ patients had bachelor's level education. Only $0.8 \%$ patients had master's level education.

Figure: 5 


\section{LITERACY LEVEL OF STUDY POPULATION}

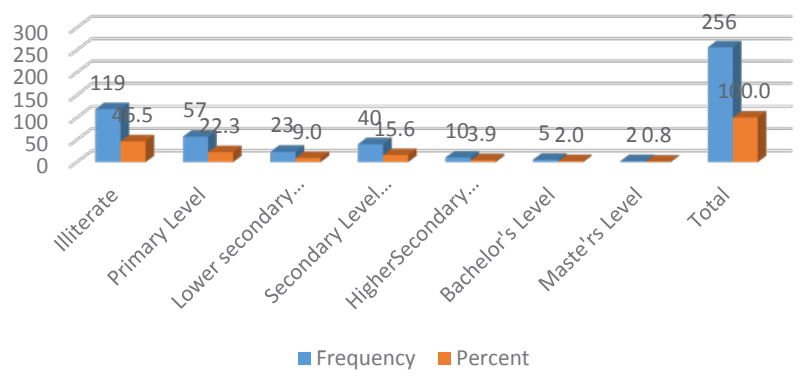

\section{Ethnicity}

RHD affected the people of all ethnicities as shown by figure 6.

\section{Figure: 6}

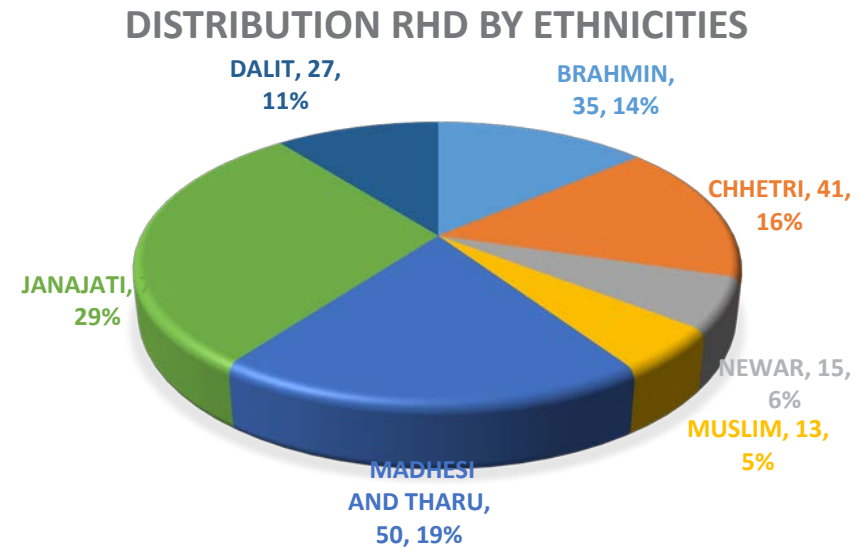

\section{Valvular Lesion}

Regarding single valvular lesion, isolated pure mitral regurgitation (MR) was present in $14.8 \%$, mitral stenosis (MS) in $9.8 \%$ and aortic regurgitation (AR) in $3.14 \%$ of patients. Cases of isolated aortic stenosis (AS) were absent. In combination, MS and MR was found in $22.7 \%$ of patients and AS and AR was found only in $1.9 \%$ of patients.

Isolated pure MS, was statistically significant in female patients with $\mathrm{p}$ value 0.013 .

Mitral valve was affected in $98.2 \%$ of patients while aortic valve was affected in $53.9 \%$ of patients. Overall, involvement of aortic valve was statistically significant in male patients with $\mathrm{p}$ value 0.013 as shown in table no 1 .

\begin{tabular}{lcccc} 
& \multicolumn{3}{c}{ Table no: 1} \\
Characteristic & $\begin{array}{c}\text { Male } \\
(\mathrm{n}=99)\end{array}$ & $\begin{array}{c}\text { Female } \\
(\mathrm{n}=157)\end{array}$ & $\begin{array}{c}\text { Overall } \\
(\mathrm{n}=256)\end{array}$ & P value \\
& & & & \\
\hline $\begin{array}{l}\text { Overall } \\
\text { Mitral Valve } \\
\text { Involvement }\end{array}$ & 95 & 156 & 251 & $0.056^{*}$ \\
\hline $\begin{array}{l}(37.85 \%) \\
\text { Overall }\end{array}$ & $752.15 \%)$ & $(98.04 \%)$ & \\
$\begin{array}{l}\text { Aortic Valve } \\
\text { Involvement }\end{array}$ & $(54.35 \%)$ & 63 & 138 & 0.013 \\
\hline
\end{tabular}

*=Likely hood ratio

\begin{tabular}{|c|c|c|c|c|}
\hline \multicolumn{5}{|c|}{ Table no: 2} \\
\hline Characteristic & $\begin{array}{c}\text { Male } \\
(\mathrm{n}=99)\end{array}$ & $\begin{array}{l}\text { Female } \\
(\mathrm{n}=157)\end{array}$ & $\begin{array}{l}\text { Overall } \\
(\mathrm{n}=256)\end{array}$ & pvalue \\
\hline $\begin{array}{l}\text { Mitral Valve } \\
\text { Involvement }\end{array}$ & $\begin{array}{c}36 \\
(36.36 \%)\end{array}$ & $\begin{array}{c}82 \\
(52.22 \%)\end{array}$ & $\begin{array}{c}118 \\
(46.09 \%)\end{array}$ & 0.013 \\
\hline $\begin{array}{l}\text { Mitral Stenosis } \\
\text { (Isolated) }\end{array}$ & $\begin{array}{c}7 \\
(7.07 \%)\end{array}$ & $\begin{array}{c}15 \\
(9.55 \%)\end{array}$ & $\begin{array}{c}22 \\
(8.59 \%)\end{array}$ & 0.49 \\
\hline $\begin{array}{l}\text { Mitral Regurgitation } \\
\text { (Isolated) }\end{array}$ & $\begin{array}{c}11 \\
(11.11 \%)\end{array}$ & $\begin{array}{c}27 \\
(17.19)\end{array}$ & $\begin{array}{c}38 \\
(14.8 \%)\end{array}$ & 0.182 \\
\hline $\begin{array}{l}\text { Combined MS and } \\
\text { MR }\end{array}$ & $\begin{array}{c}18 \\
(18.18 \%)\end{array}$ & $\begin{array}{c}40 \\
(25.47 \%)\end{array}$ & $\begin{array}{c}58 \\
(22.7 \%)\end{array}$ & 0.174 \\
\hline $\begin{array}{l}\text { Aortic Valve } \\
\text { Involvement }\end{array}$ & $\begin{array}{c}4 \\
(4 \%)\end{array}$ & $\begin{array}{c}1 \\
(0.6 \%)\end{array}$ & $\begin{array}{c}5 \\
(1.9 \%)\end{array}$ & $0.056^{*}$ \\
\hline $\begin{array}{l}\text { Aortic Stenosis } \\
\text { (Isolated) }\end{array}$ & $\begin{array}{c}0 \\
(0 \%)\end{array}$ & $\begin{array}{c}0 \\
(0 \%)\end{array}$ & $\begin{array}{c}0 \\
(0 \%)\end{array}$ & 0 \\
\hline $\begin{array}{l}\text { Aortic Regurgitation } \\
\text { (Isolated) }\end{array}$ & $\begin{array}{c}3 \\
(3 \%)\end{array}$ & $0(0 \%)$ & $\begin{array}{c}3 \\
(1.17 \%)\end{array}$ & $0.016^{*}$ \\
\hline Combined AS+AR & $\begin{array}{c}1 \\
(1 \%)\end{array}$ & $\begin{array}{c}1 \\
(0.6 \%)\end{array}$ & $\begin{array}{c}2 \\
(0.78 \%)\end{array}$ & $0.774^{*}$ \\
\hline $\begin{array}{l}\text { Multivalve (Aortic } \\
\text { and Mitral) } \\
\text { involvement }\end{array}$ & $\begin{array}{c}59 \\
(59.6 \%)\end{array}$ & $\begin{array}{c}74 \\
(47.13 \%)\end{array}$ & $\begin{array}{c}133 \\
(51.9 \%)\end{array}$ & 0.052 \\
\hline
\end{tabular}

*=Likely hood ratio

In overall valvular lesion isolated as well as in combination, MR was the most common valvular lesion present in $82.03 \%$ of patients, MS was present in $65.02 \%$ of patients and it was statistically significant in female patients with p value 0.01

AR was present in $49.6 \%$ of patients and was statistically significant in male patients with $\mathrm{p}$ value 0.013 , while AS was present in $21.9 \%$ of patients as shown in table no 3 .

\begin{tabular}{|c|c|c|c|c|}
\hline \multicolumn{5}{|c|}{ Table no: 3} \\
\hline Characteristic & $\begin{array}{l}\text { Male } \\
(\mathrm{n}=99)\end{array}$ & $\begin{array}{l}\text { Female } \\
(\mathrm{n}=157)\end{array}$ & $\begin{array}{l}\text { Overall } \\
(\mathrm{n}=256)\end{array}$ & pvalue \\
\hline \multicolumn{5}{|c|}{ Mitral valve lesion } \\
\hline $\begin{array}{l}\text { Over all Mitral } \\
\text { stenosis }\end{array}$ & $\begin{array}{c}55 \\
(55.56 \%)\end{array}$ & $\begin{array}{c}112 \\
(71.33 \%)\end{array}$ & $\begin{array}{c}167 \\
(65.02 \%)\end{array}$ & 0.01 \\
\hline $\begin{array}{l}\text { Overall Mitral } \\
\text { regurgitation }\end{array}$ & $\begin{array}{c}83 \\
(83.83 \%)\end{array}$ & $\begin{array}{c}127 \\
(80.89 \%)\end{array}$ & $\begin{array}{c}210 \\
(82.03 \%)\end{array}$ & 0.55 \\
\hline \multicolumn{5}{|c|}{ Aortic Valve lesion } \\
\hline $\begin{array}{l}\text { Overall aortic } \\
\text { Stenosis }\end{array}$ & $\begin{array}{c}28 \\
(28.28 \%)\end{array}$ & $\begin{array}{c}28 \\
(17.83 \%)\end{array}$ & $\begin{array}{c}56 \\
(21.90 \%)\end{array}$ & 0.049 \\
\hline $\begin{array}{l}\text { Overall Aortic } \\
\text { Regurgitation }\end{array}$ & $\begin{array}{c}59 \\
(56.59 \%)\end{array}$ & $\begin{array}{c}68 \\
(43.31 \%)\end{array}$ & $\begin{array}{c}127 \\
(49.60 \%)\end{array}$ & 0.011 \\
\hline
\end{tabular}

\section{Multi-valvular lesion}

Both mitral and aortic valve were affected in $51.9 \%$ of patients and the most common combinations were MR and AR (27.07\%) and MS., MR. and AR (27.07\%). The combination of $\mathrm{MR}$ and AR was significant in male patients with $\mathrm{p}$ value 0.009 .

\begin{tabular}{lcccc}
\hline Characteristic & $\begin{array}{c}\text { Male } \\
(\mathrm{n}=99)\end{array}$ & $\begin{array}{c}\text { Female } \\
(\mathrm{n}=157)\end{array}$ & $\begin{array}{c}\text { Overall } \\
(\mathrm{n}=256)\end{array}$ & pvalue \\
\hline $\begin{array}{l}\text { Multi valve (Aortic } \\
\text { and Mitral) lesion }\end{array}$ & 59 & 74 & 133 & \\
\hline & $(44.36 \%)$ & $(55.64 \%)$ & $(51.96 \%)$ &
\end{tabular}




\begin{tabular}{|ccccc}
\hline MS+ AS & 0 & 4 & 4 & $0.047^{*}$ \\
& $(0 \%)$ & $(5.4 \%)$ & $(3 \%)$ & \\
\hline MS+AR & 2 & 5 & 7 & $0.570^{*}$ \\
& $(3.38)$ & $(6.76 \%)$ & $(5.26 \%)$ & \\
\hline MR+AR & 21 & 15 & 36 & 0.009 \\
& $(35 \%)$ & $(20.27 \%)$ & $(27.07 \%)$ & \\
\hline MR+AS & 2 & 0 & 2 & $0.05^{*}$ \\
& $(3.38)$ & $(0 \%)$ & $(1.5 \%)$ & \\
\hline MR+AS+AR & 6 & 2 & 8 & $0.034^{*}$ \\
\hline MS+AS+AR & $(10.17)$ & $(2.7 \%)$ & $(6.02 \%)$ & \\
\hline MR +MS+AR & 3 & 5 & 8 & $0.945^{*}$ \\
& $(5.08 \%)$ & $(6.77 \%)$ & $(6.02 \%)$ & \\
\hline MS+MR+AS & 9 & 27 & 36 & 0.069 \\
\hline MS+MR+AS+AR & $(15,25 \%)$ & $(36.49 \%)$ & $(27 . .07 \%)$ & \\
& $(3.38)$ & $(4.05 \%)$ & $(3.76 \%)$ & $0.951^{*}$ \\
& $(23.73 \%)$ & $(17.57 \%)$ & $(20.30 \%)$ & $0.137^{*}$ \\
\hline
\end{tabular}

*=Likely hood ratio

\section{Discussion}

Rheumatic heart disease is a major public health problem of developing countries like Nepal affecting mainly children, young adults and people with poor socioeconomic status. In our study $46.5 \%$ of the patients were illiterate, $2 \%$ had bachelor's level education and $0.8 \%$ had master's level education. Majority of patients had no regular income source. So, in Nepal RHD seems to be mainly the disease of poor, illiterate and people with low education level.

Like many other studies, this study also showed that RHD is disease of children and young people. In our study RHD was more common among patients of age group 10-40 years, Similar to our study, in a study done by Laudari $S$ et al, majority of the patients were of productive age group and with low socioeconomic status ${ }^{11}$. Similarly, in the study of Kafle RC et al $50 \%$ of the patients belonged to age group $21-40$ years. ${ }^{12}$

\section{Geographical distribution of RHD}

In this study majority of the admitted patients were from Central Development Region followed by Western and Eastern Development Region The main reason for this might be easy availability of health services and transportation facilities, awareness about the disease among the people and high population density. Least number of patients were admitted from Far Western Region; however, this does not mean that the prevalence of RHD is less in this region. The main reason for this might be, less number of patients were able to come to Kathmandu for their treatment. due to poverty, difficult transportation, lack of awareness about the disease, lack of local hospitals which could refer the patients. Besides this, easy access to India might be another cause. Regarding zones, least number of patients were admitted from Karnali Seti and Mahakali. The reasons for this might be same as mentioned above. Thus, the burden of RHD is more or less equally distributed all over Nepal.

\section{Affected valve and valvular lesion}

According to Essop MR et al approximately 25\% of patients with rheumatic heart disease have isolated MS and approximately $40 \%$ have combined MS and MR. Multivalve involvement is seen in $38 \%$ of patients with MS, with the aortic valve affected in approximately $35 \% .{ }^{10}$ In our study, mitral valve was the most commonly affected valve (98.2\%) followed by aortic valve (53.9\%). Mitral valve involvement was more common in female. Involvement of aortic valve was statistically significant in male patients with p value 0.01 .

Other studies that were done previously have shown more or less similar result. In a previous study done in SGNHC by Malla $\mathrm{R}$ et al, mitral valve was the most commonly involved valve (78.8\%). MS was most common lesion followed by MR while AS was the least common lesion. Mitral valve disease was more common in female whereas aortic valve disease was more common in male. ${ }^{13}$ In another study done by Rayamajhi A et al, mitral valve was the most commonly affected valve $(82 \%){ }^{14}$

In our study, isolated mitral valve was affected more $(46.05 \%)$ than isolated aortic valve $(1.9 \%)$ which was statistically significant in female patients with p value 0.013 . Similar to our study, in the study done by. Laudari S et al, isolated mitral valve was the most commonly affected valve (46.80\%) followed by isolated aortic valve (9.36\%). ${ }^{11}$ Similarly, in the study of Manjunath $\mathrm{CN}$ et al, mitral valve was most commonly affected valve followed by aortic valve ${ }^{15}$. In a study done in Sudan, isolated mitral valve was affected in $60 \%$ of patients while aortic valve in $7 \% .{ }^{16}$

In our study, multivalve involvement (Mitral as well as Aortic valve) was found in $51.9 \%$ patients. Most of the patients were admitted either with complication or for valve replacement surgery, which might be the reason for high prevalence of multivalve involvement. Usually, majority of the cases of isolated MS first go for Percutaneous Transvenous Mitral Commissurotomy. So, cases of pure MS were less in our study.

In overall valvular lesion, isolated as well as in combination, MR was the most common valvular lesion presented in $82.03 \%$ of patients. MS was present in $65.02 \%$ of patients and was statistically significant in female patients with p value 0.01 . Similar to our study, in a study done by Al-Khalifa, MS et al, and Shrestha NR et al, MR was the most common valvular lesion across all age groups. ${ }^{16,17}$

Overall, aortic regurgitation was present in $49.6 \%$ of patients while AS was present in only $21.9 \%$ patients. Involvement of both AR and AS was significant in male patients with $\mathrm{p}$ value 0.013 and 0.045 respectively. In other studies, also, AR was more common in male as compared to female. ${ }^{11,17}$ In our study isolated, pure, mitral stenosis was present in $9.8 \%$ of patients. Similarly, in the study of Laudari $\mathrm{S}$ et al and Kafle RC et al isolated MS was found in, $13.61 \%$ and $6.82 \%$ of patients respectively. ${ }^{11,12}$, Regarding multi valvular lesion, the most common combination was MR and AR 27.07\%. Similarly, MR and AR was the most common finding (17.9\%), in the study of Shrestha NR et al. ${ }^{17}$

The limitations of our study is that it was a single center study, so the results might not be the true representation of whole country. The sample size was also small.

Nepal is facing a huge burden of RHD where a lot of children, young and adult people are losing their productive age of life in hospital's bed and losing their life prematurely. This type of study by providing some basic pattern of RHD will help the concerned people to initiate and implement the programme for the reduction of burden of RHD in Nepal. It will eventually help to save the life of many young patients

\section{Conclusion}

RHD mainly affects children and young people of low socioeconomic group. In our study, mitral valve was the most commonly affected valve and mitral regurgitation was the most common valvular lesion. Mitral stenosis was statistically 
significant in female patients while aortic regurgitation as well as aortic stenosis was significant in male patients.

\section{Conflict of interest}

The authors do not have any conflict of interest including financial in publication of this article

\section{References}

1. Carapetis JR, Currie BJ, Mathews JD Cumulative incidence of rheumatic fever in an endemic region: a guide to the susceptibility of the population? Epidemiol Infect 2000; 124:239-44. https://doi.org/10.1017/S0950268800003514

2. Carapetis JR, Steer AC, Mulholland EK, Weber M. The global burden of group A streptococcal disease. Lancet Infect Dis 2005; 5:685-694. https://doi.org/10.1016/S14733099(05)70267-X

3. World Health Federation Fact sheet 2016

4. World Health Statistical Annual 1990-2000 Geneva, World Health Organization.

5. Jose VJ, Gomathi M Declining prevalence of rheumatic heart disease in rural schoolchildren in India2001-2002. Indian Heart J 2003; 55:158-60.

6. Marijon E, Ou P, Celermajer DS Ferreira, B et al Prevalence of rheumatic heart disease detected by echocardiographic screening. N Engl J Med 2007; 357:470-6. https://doi. org/10.1056/NEJMoa065085

7. Ahmed J, Mostafa Zaman M, Monzur Hassan MM. Prevalence of rheumatic fever and rheumatic heart disease in rural Bangladesh. Trop Doct 2005; 35:160-1. please add at the end: https://doi.org/10.1258/0049475054620879

8. Periwal KL, Gupta BK, Panwar RB, Khatri PC et al. Prevalence of rheumatic heart disease in school children in Bikaner: an echocardiographic study.J Assoc Physicians India 2006; 54:279-82.

9. World Heart Federation criteria for echocardiographic diagnosis of rheumatic heart disease-an evidence-based guideline Bo Reményi, Wilson N, Steer A, Ferreira B, Joseph KadoJ,et al, Nature Review ICardioloy 2012 May;9: I297-

Cite this article as: Prabha Chapagain Koirala, Ram Kishor. Sah, Deewaker Sharma. Pattern of rheumatic heart disease in patients admitted at tertiary care centre of Nepal. Nepalese Heart Journal 2018; 15(1): 29-33.

http://dx.doi.org/10.3126/njh.v15i1.19713
309

10. Essop MR, Nkomo VT: Rheumatic and non rheumatic valvular heart disease: Epidemiology management, and prevention in Africa. Circulation 2005 Dec 6;112(23):584-91. https://doi.org/10.1161/CIRCULATIONAHA.105.539775

11. Laudari S and . Subramanyam G. A study of spectrum of rheumatic heart disease in a tertiary care hospital in Central Nepal. Int J Cardiol Heart Vasc. 2017 Jun; 15: 26-30.

12. Kafle RC, Alurkar VM, Paudel N, Jha GS RHD Pattern of Valvular Involvement in Rheumatic Heart Disease Patients in a Tertiary Care Hospital of Western Nepal Nepalese Heart Journal,2016 Vol 13, No. 29-31

13. Malla R, Thapaliya S, Gurung P, Bogati A et al, Patterns of Valvular Involvement in Rheumatic Heart Disease patients taking Benzathine Penicillin at Shahid Gangalal National Heart Centre, Kathmandu, Nepal Nepalese Heart Journal 2016; 13(2): 25-27

14. Rayamajhi A, Sharma D, Shakya U. Clinical, laboratory and echocardiographic profile of acute rheumatic fever in Nepali children. Ann Trop Paediatr. 2007 Sep;27(3):169-77. https:// doi.org/10.1179/146532807X220271

15. Manjunath CN, Srinivas P, Ravindranath KS, Dhanalakshmi $\mathrm{C}$ et al, Incidence and patterns of valvular heart disease in a tertiary care high-volume cardiac center: a single center experience. Indian Heart J. 2014 May-Jun;66(3):320-6. https://doi.org/10.1016/j.ihj.2014.03.010

16. Alkhalifa MS. Ibrahim S.A and Osman S.H Pattern and severity of rheumatic valvular lesions in children in Khartoum, Sudan Eastern Mediterranean Health Journal EMHJ, 2008, 14(5): 1015-1021.

17. Shrestha NR, Pilgrim T, Karki P, Bhandari R et al Rheumatic heart disease revisited: patterns of valvular involvement from a consecutive cohort in eastern Nepal. J Cardio -vasc Med (Hagerstown). 2012 Nov;13(11):755-9. https://doi. org/10.2459/JCM.0b013e32835854b6 